2. Đàm Văn Việt(2013): " Nghiên cứu điều trị mất răng hàm trên tứng phần bằng kĩ thuật implant có ghép xương".'Luân án tiến sĩ y học. Đại học Y Hà Nội.

3. Đoan Thanh Giang (2010): " Nhận xét kết quả cấy ghép implant nha khoa trong điêuu trị phục hình răng cố định bằng implant của hãng Noble Biocare". YHTH(722) - Số 6/2010

4. Nguyễn Mạnh Hùng (2020): " Đánh giá kết quả cây ghép tức thì vùng răng sau bằng hệ thống implant Neodent tai Bênh viên Đại hoc Y Hải Phòng". Luận văn Bác sî̃ chuyên khoa Cấp II. Đại hoc Y dược Hải Phòng

5. Trương Uyên Cường (2016): " Đánh giá kết quả cấy ghép nha khoa vưng răng sau hàm trên có nâng xoang sử dụng xương đồng loại đông khô khử khoáng VBKC-09.02". Tạp chí Y dược lâm sàng 108. Tập 11 số 5/2016

6. Misch C.(2007). Maxillary sinus anatomy, pathology and graft surgery. Contemporary

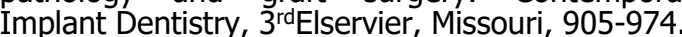

7. Vasilena Ivanova (2021), Correlation between primary, secondary stability, bone density, percentage of vital bone formation and implant size. Int J Environ Res Public Health 2021 Jun 30; 18(13):6994 doi: 10;3390/ijerph 18136994.

8. Andre Hsu (2016), Comparison of Initial Implant Stability of Implants Placed Using Bicortical Fixation, Indirect Sinus Elevation, and Unicortical Fixation.Int J Oral Maxillofac Implants. Mar-Apr 2016;31(2):459-68. doi: 10.11607/jomi.4142

\title{
ỨNG DỤNG KĨ THUÂT GIẢI TRÌNH TỰ THẾ HỆ MỚI KHẢO SÁT ĐộT BIẾN GEN GÂY BỆNH PARKINSON
}

Đỗ Đức Minh ${ }^{1}$, Lương Bắc An ${ }^{1}$, Lê Gia Hoàng Linh ${ }^{1}$, Trần Ngọc Tài ${ }^{2}$, Mai Phương Thảo ${ }^{1}$

\section{TÓM TẮT}

Muc tiêu: Parkinson là bênhh lí đăc trưng bởi quá trình diễn tiến và thái hoá có chọn lọc của các tế bào dopaminergic ở phần đắc chất đen. Đây là mô̂t trong những bệnh lí thái hoá thần kinh phổ biến nhất hiện nay. Mặc dù bệnh Parkinson được nghiên cứu kĩ lưỡng ở nhiều đỗ tuổi, nhưng cơ chế bệnh sinh của Parkinson vẫn chưa rõ ràng. Các yễu tố di truyền và môi trường được cho là đóng vai trò quan trọng trong tương tác với căn nguyên của bệnh. Với sự phát triển nhanh chóng của các nghiên cứu gần đây, yếu tố di truyền đóng một vai trò quạn trọng trong sự tiến triển của Parkinson. Mục tiêu: Úng dụng kĩ thuật giải trình tự thế hệ mới khảo sát nhóm 20 gen gây bệnh Parkinson. Đối tượng và phương pháp: 60 bệnh nhân được chẩn đoán mắc bệnh Parkinson dựa trên triệu chứng và thang điểm MDS-UPDRS. DNA được tách chiết từ máu ngoại biên, thực hiện phản ứng phân mảnh DNA và chuẩn bị thư viện phục vụ giải trình tự. Dữ liệu giải trình tự được phân tích bắng phần mềm BASESPACE nhằm xác định đột biến của 20 gen khảo sát. Kết quả: Trong 60 bệnh nhân tham gia nghiên cứu, chúng tôi ghi nhận 10 trường hợp mang đột biến gen, gồm R1628P gen LRRK2 (6 trường hợp), c.115+1C > T (2 trường hợp) và L444P (1 trường hợp) gen GBA và A80T gen PLA2G6 (1 trường hợp). Kết luân: Nghiên cứu ứng dụng thành công kỹ thuật NGS phát hiện các đột gen gẩy bệnh Parkinson, góp phân giúp ích cho viêc xét nghiêm gen chẩn đoán xác định bệnh lí Parkinson. Từ khoá: Parkinson, NGS, DNA

${ }^{1}$ Đai hoc Y Dước TPHCM

2Bệnh viện Đại học Y Dược TPHCM

Chịu trách nhiệm chính: Mai Phương Thảo

Email: drmaithao@ump.edu.vn

Ngày nhận bài: 13.8.2021

Ngày phản biên khoa hoc: 11.10.2021

Ngày duyệt bài: 20.10.2021

\section{SUMMARY}

APPLICATION NEXT GENERATION SEQUENCING IN DETECTING MUTATIONS OF PARKINSON'S DISEASE CAUSING GENES

Background: Parkinson's disease, characterized by the progressive and selective degeneration of substantia nigra dopaminergic neuron, is one of the most common neurodegenerative disorders. Although Parkinson's disease has been investigated intensely for ages, the pathogenesis of Parkinson's disease remains indistinct. Genetic and environmental factors maybe play an interactional role in the etiology of Parkinson's disease. However, with the rapid growth of recent studies, genetic factors play a crucial role in the progression of Parkinson's disease. Objectives: Nextgeneration sequencing (NGS) has been used to detect mutations on 20 genes relating to Parkinson's disease. Methods: Blood samples were collected from 60 Parkinson's patients based on their clinical symptoms and MDS-UPDRS scores. DNA was extracted from peripheral blood samples of patients. DNA was fragmented and prepared library to conducting sequencing. BASESPACE software was used for data analysis. Results: From 60 Parkinson's patients, we detected 10 patients $(16,7 \%)$ had pathogenic mutations, including LRRK2 R1628P (6 cases), GBA c. $115+1 \mathrm{C}>\mathrm{T}$ (2 cases), GBA L444P (1 cases) và PLA2G6 A80T (1 case). Conclusion: NGS was successfully applied to identify mutants in Parkinson's genes, helping to test for diagnostic genes to determine Parkinson's genetic neuropathy.

Keywords: Parkinson's disease, next generation sequencing, mutation

\section{I. ĐẶT VẤN ĐỀ}

Bệnh lý Parkinson (Parkinson's disease - PD) là bệnh lý thoái hóa thần kinh phổ biến thứ hai 
sau bệnh Alzheimer, với các đặc điểm: run không chủ ý, yễu cơ, dáng đi khom về phía trước. Không có tiêu chuẩn chẩn đoán bênh học thần kinh rõ ràng cho bệnh Parkinson cũng như độ nhạy, độ đặc hiệu của những tiêu chuẩn này chưa được xác định rõ ràng. Căn nguyên gây bênh Parkinson vấn chưa được hiểu rõ. Một số yểu tố như di truyền, môi trường, stress oxy hóa, rối loạn chức năng ty thể... được ghi nhận có liên quan đến sự phát triển bệnh. Hầu hết các giả thuyết cho rằng bệnh do sự phối hợp giữa yếu tố môi trường và di truyền. Đến nay đã có 23 gene và locus được xác dịnh có liên quan với bệnh $\mathrm{PD}$ và được đặt tên là gene "PARK". Trong đó, 8 gene và locus là PARK3, 5, 11, 13, 18, 21, 22, 23 vẫn chưa được phân nhóm chính xác và 3 gene/ locus được xếp vào nhóm yếu tố nguy cơ của PD(1).

Tại Việt Nam, các nghiên cứu về đề tài Parkinson còn khá ít, được thực hiện trong khoảng 5 - 6 năm gân đây và phần lớn là khảo sát đặc điểm lâm sàng (triêuu chứng vận động, ngoài vận động) và chất lượng cuộc sống của bệnh nhân Parkinson. Để phát hiện các biến đổi di truyền, các phương pháp dựa trên PCR (phản ứng chuối - Polymerase Chain Reaction) có thể được sử dụng. Tuy nhiên, hạn chế của phương pháp dựa trên PCR là chỉ phát hiện một số ít đột biến đã biết trước trên một số lượng gene giới hạn, không thể nhận biết những đột biến mới. Giải trình tự Sanger là phương pháp chuẩn vàng để phát hiện đột biến gen, tuy nhiên giá thành cao và mối phản ứng chỉ giải được trình tự của một phân mảnh DNA, làm giới hạn tổng lượng trình tự được giải, độ nhạy thấp (không thể phát hiện những đột biến có tần suất thấp hơn $20 \%$ ), không thế phát hiện đột biến thêm hoặc mất đoạn lớn (indel) và chuyển đoạn (translocation).

Các nghiên cứu về di truyền học Parkinson hiên nay trên thế giới thường sử dụng kỹ thuật Giải trình tự gene thế hệ mới (NGS: Next generation sequencing), cho phép giải trình tự đồng thời hàng triệu phân mảnh DNA trong một phản ứng, giúp phẩn tích kết quả nhanh và giảm giá thành xét nghiệm. Hiện nay phương pháp giải trình tự trúng đích (targeted sequencing) thay vì giải trình tự cả bộ gene (whole geneome sequencing: WGS) được sử dung phổ biến trong giải trình tự các gene muc tiểu. Với ưu điểm là thông lượng giải trình tự lớn, thực hiện nhiều mẫu cùng lúc và có độ chính xác cao, chúng tôi thực hiện nghiên cứu ứng dụng kĩ thuật giải trình tự thế hệ mới khảo sát đồng thời 20 gen có tần suất đột biến cao và liên quan bệnh lí Parkinson.

\section{II. ĐỐl TƯƠNG VÀ PHƯƠNG PHÁP NGHIÊN CỨU Thiết kế nghiên cứu: Nghiên cứu mô tả cắt ngang}

Đối tượng nghiên cứu. 60 bệnh nhân được chẩn đoán mắc bênh Parkinson theo tiêu chuẩn chẩn đoán của Hiêp hội Parkinson và Rối loạn vận động quốc tế (International Parkinson and Movement Disorder Society Clinical Diagnostic Criteria for Parkinson's disease) tai phòng khám Thần kinh, bệnh viện Đại học Y Dược Thành phố Hồ Chí Minh và đồng ý tham gia nghiên cứu. Bệnh nhân có hội chứng Parkinson thứ phát hoặc bệnh nhân không đồng ý tham gia nghiên cứu sẽ thuộc tiêu chuẩn loại trừ.

Phương pháp nghiên cứu. Bệnh nhân đồng ý tham gia nghiên cứu được lấy $2 \mathrm{ml}$ máu ngoại biên chứa trong ống EDTA Vacutanier (Becton Dickinson) và giữ mát $4^{\circ} \mathrm{C}$ không quá 24h trước khi tiến hành tách chiết DNA. Mẫu máu toàn phần được tách chiết DNA bằng bộ kít QIAamp DNA Blood Mini kit (QIAGEN) theo hướng dẫn của nhà sản xuất. DNA sau tách chiết được kiểm tra bằng máy Nanodrop ${ }^{\mathrm{TM}}$ 2000/2000c Spectrophotometer (ThermoFisher) để xác định nồng độ và độ tinh sạch.

500ng DNA sẽ được phân mảnh bằng enzyme fragmentase (NEBNext dsDNA Fragmentase). Phản ứng phân cắt được thực hiên tại $37^{\circ} \mathrm{C}$ trong 30 phút. Sản phẩm sau phẩn cắt được tinh sach và chọn kích thước bằng KAPA pure bead, với tỉ lệ bead sử dụng lần lượt là $0.65 X$ và $1 X$ để chọn ra được các phân mảnh DNA có kích thước tập trung tại $150 \mathrm{bp}-300 \mathrm{bp}$. Sản phẩm sau tinh sạch được kiểm tra kích thước bằng điện di trên gel Agarose. DNA sau phân mảnh được tiến hành sứa đuôi (NEBNext FFPE DNA Repair Mix) và chuẩn bị thư viện (NEBNext Ultra II DNA Library Prep Kit for Illumina). Các bước tiến hành theo hướng dẫn của nhà sản xuất.

$400 \mathrm{ng}$ sản phẩm từ bước tao thư viên của mẫu sẽ được tiến hành lai với hỗn hợp mẫu dò đặc hiệu cho 20 gene mục tiêu (SNCA, LRRK2, GCH1, UCHL1, PARK7, ATP13A2, PINK1, PARK2, CHCHD2, DNAJC13，DNAJC6, EIF4G1，FBXO7, GBA, HTRA2, MAPT, PLA2G6, SYNJ1, VPS35 và VPS13C) - qui trình theo bộ hoá chất xGen Lockdown Reagents. Giải trình tự được thực hiện trên hệ thống Illumina MiniSeq với bộ hoá chất MiniSeq Mid output kits (300 cycles), đạt độ phủ trung bình $30 \mathrm{X}$. Dữ liệu giải trình tự được xuất dưới định dạng base call file (.bcl), các cặp trình tự (pair-end reads - $\mathrm{PE}$ ) của các mẫu khác nhau được phân nhóm (demultiplex) thông qua trình tự nhận diện 8-bp (barcode) có trên trình tự 
index P7 và P5 bằng công cụ bcl2fastq (Illumina). Dũ liệu trình tự mỗi mấu bệnh nhân được xuất ra file Fastq và được phân tích bằng phần mềm thương mại BASESPACE (Illumina).

Các đội biến được xác định bằng phần mềm BASESPACE sẽ được khẳng định lại bằng công cụ giải trình tự Sanger với quy trình đã được công bố trước đầy $(2,3)$.

Y đức của nghiên cứu. Nghiên cứu được tài trợ bởi Quỹ phát triển khoa học và công nghệ thành phố Hồ Chí Minh (55/2020/HĐ-QPTKHCN) và được chấp thuận bởi hội đồng y đức Đại học Y Dược TPHCM (352/HĐĐĐ-ĐHYD).

\section{KẾT QUẢ NGHIÊN CỨU}

Đặc điểm lâm sàng mẫu nghiên cứu. Trong thời gian từ tháng 09/2020 đến tháng $06 / 2021$, số lượng mấu thu được là 60 bệnh nhân Parkinson. Trong đó, bệnh nhân có độ tuổi trung bình là 58,5 tuổi, với tuổi nhỏ nhất là 31 tuổi và lớn tuổi nhất là 81 tuổi. Nữ giới mắc bệnh nhiều hơn nam giới với tỉ lệ lần lượt là $55 \%$ và $45 \%$. Về độ tuổi khởi phát bệnh, tỉ iệ bệnh nhân khởi phát sớm (dưới 50 tuổi) chiếm $40 \%$, còn lại là nhóm bệnh nhân khởi phát muộn (trên 50 tuổi) chiếm $58,3 \%$ và 1 trường hợp không ghi nhận độ tuổi khởi phát (1,7\%) (Bảng 1).

Bảng 1: Đặc tính lâm sàng của bệnh nhân UT tham gia nghiên cứu

\begin{tabular}{|c|c|c|c|}
\hline \multicolumn{2}{|c|}{ Đăc điểm lâm sàng } & $\begin{array}{c}\mathbf{N}= \\
\mathbf{6 0}\end{array}$ & $\begin{array}{c}\text { Phân } \\
\text { trăm } \\
\mathbf{( \% )}\end{array}$ \\
\hline \multirow{2}{*}{$\begin{array}{c}\text { Giới } \\
\text { tính }\end{array}$} & Nam & 27 & 45 \\
\hline \multirow{2}{*}{ Tuổi } & Nữ & 33 & 55 \\
\cline { 2 - 4 } & Thung bình \pm SD & \multicolumn{2}{|c|}{$58,5 \pm 11$} \\
\cline { 2 - 4 } & Cao nhất & \multicolumn{2}{|c|}{31} \\
\hline \multirow{2}{*}{$\begin{array}{c}\text { Tuối } \\
\text { khởi } \\
\text { phát }\end{array}$} & $>50$ tuối & \multicolumn{2}{|c|}{81} \\
\cline { 2 - 4 } & Không xác định & 24 & 58,3 \\
\cline { 2 - 4 } & Khối & 1 & 1,7 \\
\hline \multirow{2}{*}{ Kết }
\end{tabular}

Kết quả tách chiết và phân mảnh DNA bộ gen. Nồng độ DNA trung bình thu được sau bước tách chiết là $46,6 \mathrm{ng} / \mu \mathrm{l}$, khoảng dao động từ 19,5 đến $81,8 \mathrm{ng} / \mu \mathrm{l}$. Độ tinh sạch của mẫu DNA sau tách chiết có tî số A260/A280 trung bình đạt 1,84. Với 500ng DNA được chúng tôi sử dụng cho phản ứng phân mảnh, nồng độ trung bình sản phẩm sau phân mảnh là $1,74 \mathrm{ng} / \mu \mathrm{l}$ với nồng độ thấp nhất là $0,172 \mathrm{ng} / \mu \mathrm{l}$ và nồng độ cao

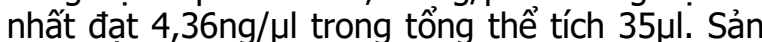
phẩm ḊNA sau phân mảnh được kiểm tra kích thước bằng điện di gel Agarose, chúng tôi ghi nhận hầu hết các sản phẩm DNA đều có kích thước tập trung tại khoảng 150-300bp (Bảng 2).

Bảng 2: Nồng độ DNA và thư viện trong nghiên cứu

\begin{tabular}{|c|c|c|}
\hline & & Nồng đô $(n g / \mu l)$ \\
\hline Nông độ & Trung bình \pm SD & $46,6 \pm 13,9 \mathrm{ng} / \mu \mathrm{l}$ \\
\hline DNA sau & Cao nhất & $81,8 \mathrm{ng} / \mu \mathrm{l}$ \\
\hline tách chiết & Thấp nhất & $19,5 \mathrm{ng} / \mu \mathrm{l}$ \\
\hline $\begin{array}{l}\text { Độ tinh } \\
\text { sach }\end{array}$ & A260/A280 & $1,84 \pm 0,05$ \\
\hline Nồng độ & Trung bình \pm SD & $1,74 \pm 0,96 \mathrm{ng} / \mu \mathrm{l}$ \\
\hline DNA sau & Cao nhất & $4,36 \mathrm{ng} / \mu \mathrm{l}$ \\
\hline $\begin{array}{l}\text { phan } \\
\text { mảnh }\end{array}$ & Thấp nhất & $0,172 \mathrm{ng} / \mu \mathrm{l}$ \\
\hline Nồng độ & Trung bình \pm SD & $30,9 \pm 15,6$ \\
\hline thư viên & Cao nhất & $6,8 \mathrm{ng} / \mu \mathrm{l}$ \\
\hline tổng & Thấp nhất & $82,4 \mathrm{ng} / \mu \mathrm{l}$ \\
\hline Nồng độ & Trung bình \pm SD & $18,6 \pm 9,1 \mathrm{ng} / \mu \mathrm{l}$ \\
\hline thư viện & Cao nhất & $2 \mathrm{ng} / \mu \mathrm{l}$ \\
\hline $\begin{array}{c}\text { gen mục } \\
\text { tiêu }\end{array}$ & Thấp nhất & $\mathrm{g} / \mu \mathrm{l}$ \\
\hline
\end{tabular}

Kết quả chuấn bị thư viện và làm giàu thư viện gen mục tiêu. Nồng độ trung bình thư viện $30,9 \mathrm{ng} / \mu \mathrm{l}$. Như vậy, sau khuếch đại thư viện trong 7 chu kì, chúng tôi ghi nhận thấy nồng độ thư viện tăng khoảng 18 lần $(30,9 \mathrm{ng} / \mu \mathrm{l}$ và $1,74 \mathrm{ng} / \mu \mathrm{l}$ ) (Bảng 2 ).

Kết quả giải trình tự. Trong 60 mẫu có kết quả giải trình tự, chúng tôi ghi nhận được 10 trường hợp bệnh nhân Parkinson có mang đột biến (chiểm 16,7\%). Trong đó, phổ biến nhất là đột biến trên gen LRRK2 chiếm 10\% (6 trường hợp), đột biến trên gen GBA chiếm 5\% (3 trường hợp) và đột biến trên gen PLA2G6 chiếm $1,7 \%$ (1 trường hợp). Tất cả các đột biến đều ở dạng dị hợp từ (tần suất đột biến từ 0,39-0,75). Các đột biến này đều được phát hiện bằng phương pháp giải trình tự Sanger.

Bảng 3: Các đột biến gây bệnh được ghi nhận ở bệnh nhân Parkinson

\begin{tabular}{|c|c|c|c|c|c|}
\hline STT & Mâu BN & Gen & dbSNP & Đột biến & Tân suất \\
\hline 1 & PD041 & GBA & rs104886460 & c.115+1C>T & 0.389 \\
\hline 2 & PD057 & GBA & rs104886460 & c.115+1C>T & 0.426 \\
\hline 3 & PD017 & GBA & rs421016 & L444P & 0.456 \\
\hline 4 & PD018 & PLA2G6 & rs121908685 & A80T & 0.75 \\
\hline 5 & PD003 & LRRK2 & rs33949390 & R1628P & 0.402 \\
\hline 6 & PD004 & LRRK2 & rs33949390 & R1628P & 0.372 \\
\hline
\end{tabular}


VIETNAM MEDICAL JOURNAL N²2 - NOVEMBER - 2021

\begin{tabular}{|c|l|l|l|l|l|}
\hline 7 & PD008 & LRRK2 & rs33949390 & R1628P & 0.419 \\
\hline 8 & PD019 & LRRK2 & rs33949390 & R1628P & 0.396 \\
\hline 9 & PD023 & LRRK2 & rs33949390 & R1628P & 0.433 \\
\hline 10 & PD054 & LRRK2 & rs33949390 & R1628P & 0.431 \\
\hline
\end{tabular}

\section{BÀN LUẬN}

Trong nghiên cứu của chúng tôi xác định được 10 trường hợp có mang đột biến trên các gen LRRK2, GBA và PLA2G6, chiếm tỉ lệ 16,7\%. Tỉ lệ này tương đương với nghiên cứu trên thế giới. Trong đó đột biến tập trung chủ yếu tại gen R1628P gen LRRK2 (6 trường hợp). Đột biến được ghi nhận này là yếu tố di truyền quan trọng gây bệnh PD ở nhóm người Hán tại Trung Quốc, Singapore và Đài Loan. Kết quả này tương tự với các nghiên cứu trước đây, cho thấy nét tương đồng trong mối liên quan giữa các đặc điểm di truyền và kiểu hình bênh lý của người Việt Nam so với dân số Châu Á(4-6). Hiện nay các nghiên cứu trong bệnh lí Parkinson đã xác định 23 gene hoặc vùng trên nhiễm sắc thể liên quan đến Parkinson có tính gia đình và di truyền theo qui luật Mendel. Phân tích sinh hóa ghi nhận sản phẩm của các gene này thường đóng đóng vai trò quan trọng cho quá trình kiểm soát chất lương protein nội bào cũng như sư dẫn truyền thần kinh, vận chuyển các chất trong tế bào thần kinh. Điều này cho thấy sự phức tạp trong sinh bệnh học của $P D$ và chỉ với các công cụ NGS, ta mới có thể phần nào xác định được nguyên nhân di truyền của bệnh lý này vì chỉ NGS mới cho phép việc giải trình tự tiết kiệm chi phí và hiệu quả nhiểu gen, các gen lớn và phức tạp ${ }^{(7-9)}$.

Đốt biến gene không phải là yễu tố duy nhất xác định căn nguyên bệnh $P D$, tuy nhiên, kết quả phân tích gene là có ý nghĩa đối với cả bác sĩ điều trị và bệnh nhân. Đối với bác sĩ điều trị, xác định gene liên quan giúp ích trong việc (1) lựa chọn phương pháp điều trị, tiên lượng khả năng đáp ứng thuốc cũng như đưa ra chiến lược điều trị phù hợp cho bệnh nhân ("cá thể hóa điều trị"); (2) tư vấn bểnh nhân và thân nhân hiểu được tình trạng bệnh lý của mình; và (3) giúp phẩn nhóm bệnh nhân trong các thử nghiệm lâm sàng. Đối với bệnh nhân và thân nhân, tùy thuộc vào kết quả phân tích gene, với sự tư vấn rõ ràng, tường tận của bác sĩ di truyền và bác sĩ điều trị sẽ giúp bệnh nhân tuân thủ điều trị, hiểu được nguy cơ bệnh truyền sang các thế hệ sau, từ đó điêu chỉnh lối sống, sinh hoạt, tầm soát bệnh.

\section{KẾT LUẬN}

Nghiên cứu ứng dụng kĩ thuật giải trình tự thế hệ mới (NGS) khảo sát đột biến của 60 mấu bệnh nhân Parkinson. Chúng tôi ghi nhận 10 trường hợp có mang đột biến trên các gen LRRK2, GBA và PLA2G6. Nghiên cứu đã bước đầu ứng dụng thành công kĩ thuật NGS để phát hiện các đột biến điểm gây bệnh Parkinson. Điều này có ý nghĩa quan trọng trong việc chẩn đoán phân loại nhóm bệnh Parkinson. Bên cạnh đó, với kết quả chẩn đoán gen giúp thuận lợi trong việc tư vấn cho gia đình, người bệnh, khu trú gen khảo sát, tầm soát người mang gen bệnh.

\section{TÀI LIẸU THAM KHẢO}

1. Lill CM, Roehr JT, McQueen MB, et al. Comprehensive research synopsis and systematic meta-analyses in Parkinson's disease genetics: The PDGene database. PLoS Genet. 2012;8(3):e1002548.

doi:10.1371/journal.pgen.1002548

2. Mai P-T, Le D-T, Nguyen T-T, et al. Novel GDAP1 Mutation in a Vietnamese Family with Charcot-Marie-Tooth Disease. BioMed Res Int. 2019;2019:7132494. doi:10.1155/2019/7132494

3. Do MD, Mai TP, Do AD, et al. Risk factors for cutaneous reactions to allopurinol in Kinh Vietnamese: results from a case-control study.

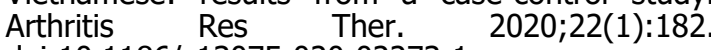
doi:10.1186/s13075-020-02273-1

4. Do MD, Pham DV, Le LP, et al. Recurrent PROC and novel PROS1 mutations in Vietnamese patients diagnosed with idiopathic deep venous thrombosis. Int J Lab Hematol. 2021;43(2):266-272. doi:10.1111/ijlh.13345

5. Tran TT, Mai TP, Tran HCB, et al. Association Between AGT M235T and Left Ventricular Mass in Vietnamese Patients Diagnosed With Essential Hypertension. Front Cardiovasc Med. 2021;8:608948. doi:10.3389/fcvm.2021.608948

6. Thao MP, Tuan PVA, Linh LGH, et al. Association of HLA-B*38:02 with Antithyroid DrugInduced Agranulocytosis in Kinh Vietnamese Patients. Int J Endocrinol. 2018;2018:7965346. doi:10.1155/2018/7965346

7. Do MD, Le LGH, Nguyen VT, et al. HighResolution HLA Typing of HLA-A, -B, -C, -DRB1 and -DQB1 in Kinh Vietnamese by Using NextGeneration Sequencing. Front Genet. 2020;11:383. doi: $10.3389 /$ fgene.2020.00383

8. Kiet NC, Khuong LT, Minh DD, et al. Spectrum of mutations in the RB1 gene in Vietnamese patients with retinoblastoma. Mol Vis. 2019;25:215-221.

9. Nguyen HT, Tran DH, Ngo QD, et al. Evaluation of a Liquid Biopsy Protocol using Ultra-Deep Massive Parallel Sequencing for Detecting and Quantifying Circulation Tumor DNA in Colorectal Cancer Patients. Cancer Invest. 2020;38(2):85-93. doi:10.1080/07357907.2020.1713350 